\title{
Use of Cellulose and Oxidized Cellulose Nanocrystals from Olive Stones in Chitosan Bionanocomposites
}

\author{
Ragab E. Abou-Zeid, ${ }^{1}$ Enas A. Hassan, ${ }^{1}$ Fedia Bettaieb, ${ }^{2,3,4}$ \\ Ramzi Khiari, ${ }^{2,3,4}$ and Mohammad L. Hassan ${ }^{1,5}$ \\ ${ }^{1}$ Cellulose and Paper Department, National Research Centre, 33 Bohouth Street, Dokki, Giza 12622, Egypt \\ ${ }^{2}$ Faculty of Science, University of Monastir, UR-CAE 13 ES 63, 5000 Monastir, Tunisia \\ ${ }^{3}$ Université Grenoble Alpes, LGP2, 38000 Grenoble, France \\ ${ }^{4}$ CNRS, LGP2, 38000 Grenoble, France \\ ${ }^{5}$ Centre of Excellence for Advanced Sciences, Advanced Materials and Nanotechnology Group, National Research Centre, \\ 33 Bohouth Street, Dokki, Giza 12622, Egypt \\ Correspondence should be addressed to Mohammad L. Hassan; mlhassan2012@yahoo.com
}

Received 20 November 2014; Revised 19 April 2015; Accepted 20 April 2015

Academic Editor: Takuya Tsuzuki

Copyright (C) 2015 Ragab E. Abou-Zeid et al. This is an open access article distributed under the Creative Commons Attribution License, which permits unrestricted use, distribution, and reproduction in any medium, provided the original work is properly cited.

Cellulose nanocrystals (CNC) and 2,2,6,6-tetramethyl-1-piperidinyloxyl- (TEMPO-) oxidized cellulose nanocrystals (CNCTEMPO) were prepared from olive stones. The prepared nanocrystals were characterized using transmission electron microscopy (TEM), Fourier transform infrared spectroscopy (FTIR), and carboxylic groups content determination. The prepared nanocrystals were used as reinforcing elements in chitosan nanocomposites, which were characterized using X-ray diffraction (XRD) and tensile strength properties. In addition, the bioactivity of the prepared chitosan nanocomposites was studied in vitro in simulated body fluid (SBF) using scanning electron microscopy (SEM) and electron diffraction X-ray spectroscopy (EDX). The results showed positive effect of the nanocrystals on tensile strength properties of chitosan and noticeable reduction in its rate of dissolution in SBF due to presence of cellulose nanocrystals. Chitosan nanocomposites containing CNC-TEMPO showed higher tensile strength properties and higher rate of dissolution in SBF than those containing cellulose nanocrystals. Nanocomposites containing CNC or CNCTEMPO could not form significant amounts of hydroxyapatite (HAp) upon immersion in SBF for up to 4 weeks. Upon addition of nanohydroxyapatite to chitosan/cellulose nanocrystals films, formation of new hydroxyapatite depositions was observed. Presence of cellulose nanocrystals in chitosan/HAp resulted in formation and deposition of higher amounts of new HAp than in case of using chitosan/HAp without cellulose nanocrystals.

\section{Introduction}

Cellulose is the most abundant natural polymer on earth followed by chitosan. While cellulose is a polysaccharide polymer consisting of $\mathrm{D}$-anhydroglucose units joined together by $1,4-\beta$ glycosidic linkages [1] chitosan is a polysaccharide polymer composed of glucosamine and $\mathrm{N}$-acetyl glucosamine units joint by $1,4-\beta$ glycosidic linkages [2]. Both polymers have many advantages such as biodegradability, biocompatibility, nontoxicity, amenability for chemical modification, reasonable strength properties, and wide availability at the industrial level. In contrast to cellulose, chitosan has an antimicrobial activity originating from the presence of amines groups and quaternary amine groups formed upon dissolving in dilute acids [3]. For that reason, chitosan finds uses in biomedical applications that require antimicrobial properties such as in drug delivery systems and tissue engineering [4]. For bone tissue engineering applications, chitosan is loaded with hydroxyapatite to induce precipitation and formation of new hydroxyapatite in the presence of simulated body fluid [5]. Cellulose nanocrystals are interesting nanomaterials having the inherent advantages 
of cellulose in addition to the unique properties of their nanosize rod-like shape and high stiffness [6,7]. Cellulose nanocrystals are prepared by acid hydrolysis of cellulose under controlled conditions. Acid hydrolysis is typically done using either hydrochloric acid or sulfuric acid. The use of sulfuric acid in the hydrolysis process leads to a more stable dispersion due to the introducing of sulfate ester groups on the surface of cellulose nanocrystals and thus prevent their agglomeration by electrostatic repulsion [8]. Due to their low density, high strength, transparency in composites, and barrier properties, cellulose nanocrystals have been investigated during the last decade as reinforcing elements with different polymer matrices for different applications [9-13]. The reinforcing effect of cellulose nanocrystals is attributed to the formation of a network that connects the well dispersed cellulose nanocrystals by hydrogen bonds at threshold ratio in polymer matrix; that threshold depends on the aspect ratio (length/width) of the nanocrystals [6]. In addition, there is a recent interest in using cellulosic nanocrystals and nanofibers in the area of tissue engineering as renewable, nanosized, low toxicity materials [14].

Olive oil and olive table production are among the important industries in the Mediterranean countries, which serve as the major production area accounting for about $98 \%$ of the world's olive cultivation [15]. The olive stones comprise the majority and more commercial interest of the waste produced in the olive industrial sector. The main use of this biomass is for producing energy. Other uses such as production of activated carbon, furfural production, plastic filler, abrasive, cosmetic, biosorbent, animal feed, or resin formation have been investigated $[15,16]$. A previous study showed that olive stones, after extraction of residual oil from them, contain considerable amount of cellulose $(\sim 54 \%)$ in addition to hemicelluloses ( 25\%) and lignin ( 26\%); olive stones were used for isolation of cellulose nanocrystals, which had close length and width to that isolated in previous studies from cotton, ramie, sisal, pine apple, wheat straw and rice straw, coir fibers, kenaf core, sugar beet pulp, rice husk, corn cobs, and some kinds of wood [17].

Due to compatibility between chitosan and cellulose nanocrystals, they have been used together in nanocomposites; the main goal was to increase tensile strength and moisture and gases barrier properties of chitosan [18-24]. Chitosan/cellulose nanocrystals nanocomposites have been also prepared for use in drug delivery applications [25]. The effect of cellulose nanocrystals on bioactivity of chitosan in bone tissue engineering applications has not been studied so far. In the current work, the effect of cellulose nanocrystals and TEMPO-oxidized cellulose nanocrystals on tensile strength properties and in vitro bioactivity and dissolution of chitosan in SBF was studied. The bioactivity of chitosan nanocomposites in SBF was investigated in the presence and absence of nanohydroxyapatite.

\section{Experimental}

2.1. Raw Materials. Olive stones of Egazi olive cultivar were collected from local market, washed with water, and pulped using $17 \% \mathrm{NaOH}$ at $160^{\circ} \mathrm{C}$ for 2 hours. The produced pulp was further bleached using sodium chlorite/acetic acid mixture according to previously published method [26]. Chemical analyses of the produced cellulose pulp was carried out according to the previously standard methods [27]: hemicelluloses (as pentosans) 14.8\% (w/w based on oven-dry sample), alpha-cellulose contents $61.2 \%$ (w/w based on oven-dry sample), ash content $1.06 \%$ (w/w based on oven-dry sample), and degree of polymerization (DP) 763. As recommended by the various standards used, all the experiments were duplicated and the difference between the two values was within an experimental error of about $5 \%$.

For preparation of simulated body fluid (SBF), reagentgrade chemicals $\mathrm{NaCl}(16.07 \mathrm{~g}), \mathrm{NaHCO}_{3}(0.71 \mathrm{~g}), \mathrm{KCl}$ $(0.45 \mathrm{~g}), \mathrm{K}_{2} \mathrm{HPO}_{4} \cdot 3 \mathrm{H}_{2} \mathrm{O}(0.462 \mathrm{~g}), \mathrm{MgCl}_{2} \cdot 6 \mathrm{H}_{2} \mathrm{O}(0.622 \mathrm{~g})$, $\mathrm{Na}_{2} \mathrm{SO}_{4}(0.144 \mathrm{~g}), \mathrm{CaCl}_{2} \cdot 2 \mathrm{H}_{2} \mathrm{O}(0.76 \mathrm{~g})$, and Tris(hydroxymethyl)aminomethane (12.236 g) in 1 Liter of deionized water were used. The $\mathrm{pH}$ value was adjusted to 7.25 at $37^{\circ} \mathrm{C}$.

Chitosan powder (high molecular weight grade, degree of deacetylation: $84.7 \%$; viscosity: $200 \mathrm{mPa} \mathrm{S}$. in $1 \%$ acetic acid; relative molar mass: Mr 400,000) and nanohydroxyapatite (particle size $<200 \mathrm{~nm}$ ) was purchased from Sigma-Aldrich and used as received.

\subsection{Preparation and Characterization of Cellulose Nanocrys-} tals. Cellulose nanocrystals were isolated from olive stones bleached pulp by acid hydrolysis using $65 \%$ sulfuric acid at $45^{\circ} \mathrm{C}$ for 45 minutes as previously described [17]. Transmission electron microscopy (TEM) of the prepared cellulose nanocrystals was carried out using a JEOL 1230 transmission electron microscope (Japan) with acceleration voltage $100 \mathrm{kV}$. A drop of cellulose nanocrystals suspension was used on a copper grid bearing a carbon film.

2.3. TEMPO-Oxidation of Cellulose Nanocrystals. TEMPOoxidized CNC were prepared according to a previously published method [28]: $1.94 \mathrm{~g}$ (4 mmol of anhydroglucose units) of cellulose nanocrystals was suspended in water $(150 \mathrm{~mL})$ containing $30 \mathrm{mg}$ of 2,2,6,6-tetramethyl-1piperidinyloxyl (TEMPO, $195 \mathrm{mmol}$ ) and $0.6 \mathrm{mg}$ of sodium bromide $(5.7 \mathrm{mmol})$ at room temperature for $30 \mathrm{~min}$. The TEMPO-mediated oxidation of the cellulose nanocrystals was initiated by slowly adding $14.7 \mathrm{~mL}$ of $13 \% \mathrm{NaClO}$ ( $20.4 \mathrm{mmol}$ ) over $20 \mathrm{~min}$ at room temperature under gentle agitation. The reaction $\mathrm{pH}$ was monitored using a $\mathrm{pH}$ meter and maintained at 10 by incrementally adding $0.5 \mathrm{M} \mathrm{NaOH}$. About $15 \mathrm{~mL}$ of methanol was then added to react with and quench the extra oxidant. After adjusting the $\mathrm{pH}$ to 7 by adding $0.5 \mathrm{M} \mathrm{HCl}$, the TEMPO-oxidized product was washed with deionized water by centrifugation and further purified by dialysis against deionized water for two days.

The carboxylic groups' content of the oxidized CNCs was determined by acid-base titration following the procedure developed for the conductometric titrations [29]. In this procedure, CNC-TEMPO samples $(50 \mathrm{mg}$ ) were suspended into $0.01 \mathrm{M}$ hydrochloric acid $(\mathrm{HCl})$ solutions $(15 \mathrm{~mL})$ with stirring. The resulting suspensions were then titrated with $0.01 \mathrm{M}$ sodium hydroxide $(\mathrm{NaOH})$ solution. 

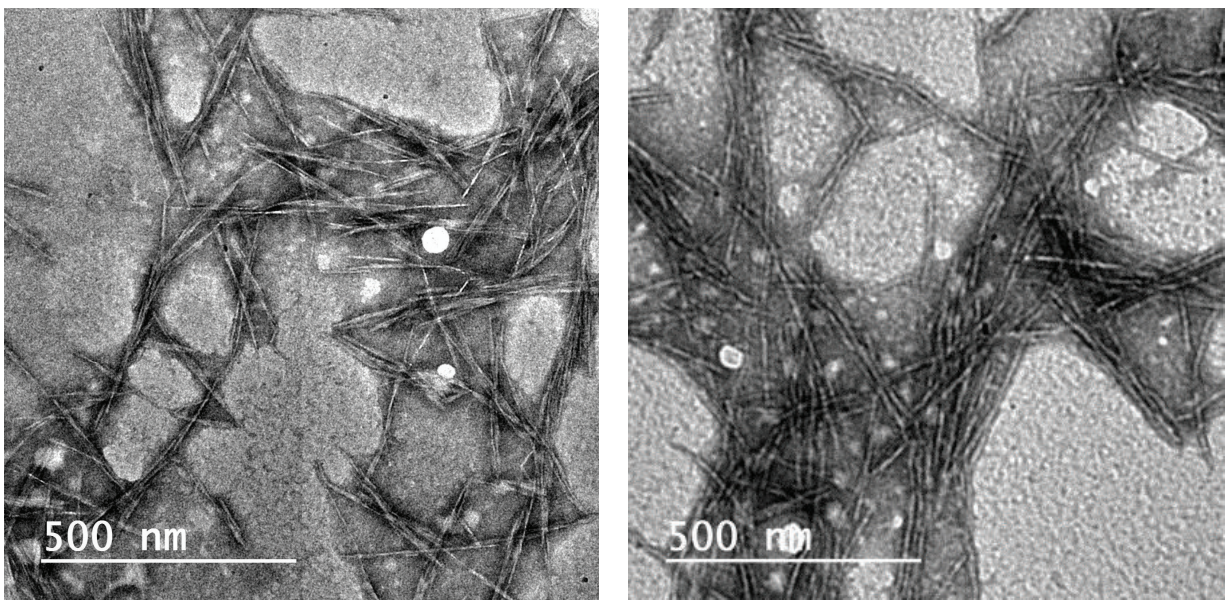

Figure 1: TEM of CNC and oxidized CNC (CNC-TEMPO).

2.4. Preparation and Characterization of Chitosan/Cellulose Nanocrystals Nanocomposites. Chitosan was dissolved in 1\% acetic acid solution; the concentration of chitosan in the solution was $1 \%$ (wt $\%$ ). Different ratios of cellulose nanocrystals (from 2.5 to $10 \%$ based on wt. of chitosan) were added to chitosan solution and the mixtures were sonicated for 4 minutes using ultrasonic processor (Keshing Sonics Vibracell, 500 Watts, Taiwan) and then stirred for 2 hours. Films were casted from chitosan/cellulose nanocrystals mixtures and dried in an oven with air circulation at $40^{\circ} \mathrm{C}$ for about 18 hours. The films were conditioned at $50 \%$ relative humidity at $25^{\circ} \mathrm{C}$ for 48 hours before testing. Tensile tests were carried out with a Lloyd instrument (Lloyd Instruments, West Sussex, United Kingdom) with a 100-N load cell. The measurements were performed at a crosshead speed of $2 \mathrm{~mm} / \mathrm{min}$ at $25^{\circ} \mathrm{C}$. Five replicates of each samples were measured and the results averaged.

The crystallinity of the extracted materials was studied by $\mathrm{X}$-ray diffraction (XRD) using X-ray diffractometer (PANalytical, Netherlands) at room temperature with a monochromatic $\mathrm{CuK} \alpha$ radiation source $(\lambda=0.154 \mathrm{~nm})$ in step-scan mode with a $2 \theta$ angle ranging from $5^{\circ}$ to $60^{\circ}$ with a step of 0.04 and a scanning time of $5.0 \mathrm{~min}$.

Surfaces of chitosan nanocomposites films were examined by FE-SEM (FEI Quanta 200 scanning electron microscope, FEI Company BV, Netherlands) with an acceleration voltage of $20 \mathrm{kV}$.

Bioactivity of chitosan nanocomposites films was studied on films containing CNC and CNC-TEMPO with or without nanohydroxyapatite; the ratio of nanohydroxyapatite to chitosan was fixed at $0.5: 1$. Samples of about $0.5 \mathrm{~g}$ were placed into SBF $(50 \mathrm{~mL})$ in an incubator at $37.0^{\circ} \mathrm{C}$ for up to 4 weeks without change of the SBF [5]. For weight measurement and FE-SEM observations of morphological changes, the samples were gently rinsed with distilled water to remove the surface SBF solution and left to dry in a desiccator. All the experiments were duplicated and the results averaged. Energy-dispersive X-ray spectroscopy was carried out using an INCA X-sight Oxford instrument attached to
FE-SEM (FEI Quanta 200 scanning electron microscope, FEI Company BV, Netherlands) to examine the newly formed hydroxyapatite (atomic and weight percent of $\mathrm{Ca}$ and P).

\section{Results and Discussion}

Figure 1 shows TEM images of cellulose nanocrystals isolated from olive stones. The width of isolated nanocrystals was in the ranges from 4 to $7 \mathrm{~nm}$ while the length was in the range from 120 to $200 \mathrm{~nm}$ [17]. Cellulose nanocrystals were oxidized by using TEMPO-mediated chlorite oxidation; the reaction selectively converts the primary hydroxyl groups at the surfaces of cellulose nanocrystals to carboxylic acids [28]. Carboxylic groups' determination of the CNC-TEMPO shows carboxylic content of $0.62 \mathrm{mmole} / \mathrm{g}$ while carboxylate content of CNC was 0.015. TEM images showed no noticeable change in width and length of CNC as a result of TEMPOoxidation; the width of CNC-TEMPO was in the range of about 4-8 nm while that of CNC was about 4-7 nm. No effect of the oxidation on the length of the nanocrystals was noticed. This is in accordance with previous findings of Habibi et al. [28], who found that oxidation of tunicate nanocrystals by TEMPO-mediated method did not affect the dimensions of tunicate nanocrystals and their crystallinity too.

The presence of the carboxylic groups on the surface of CNC-TEMPO was also proved using FTIR spectroscopy (Figure 2). The spectra showed the known peaks for cellulose, namely, a peak at $3400 \mathrm{~cm}^{-1}$ for the $\mathrm{O}-\mathrm{H}$ stretching vibration, a peak at $2900 \mathrm{~cm}^{-1}$ for the stretching vibration of $\mathrm{CH}$ and $\mathrm{CH}_{2}$ groups, a peak at $1640 \mathrm{~cm}^{-1}$ for the adsorbed water, peaks at $1430 \mathrm{~cm}^{-1}, 1372 \mathrm{~cm}^{-1}$, and $1330 \mathrm{~cm}^{-1}$ for bending vibration of $\mathrm{CH}_{2}$ and $\mathrm{OH}$ groups, peaks at $1150 \mathrm{~cm}^{-1}$, $1100 \mathrm{~cm}^{-1}$, and $1050 \mathrm{~cm}^{-1}$ for the stretching vibration of $\mathrm{C}-\mathrm{O}$ for the glycosidic bonds, C-O of primary and secondary hydroxyl groups, and a peak at $897 \mathrm{~cm}^{-1}$ for out-of-plane deformational vibration of $\mathrm{O}-\mathrm{H}$ groups [30]. As a result of oxidation of cellulose, CNC-TEMPO showed a peak 


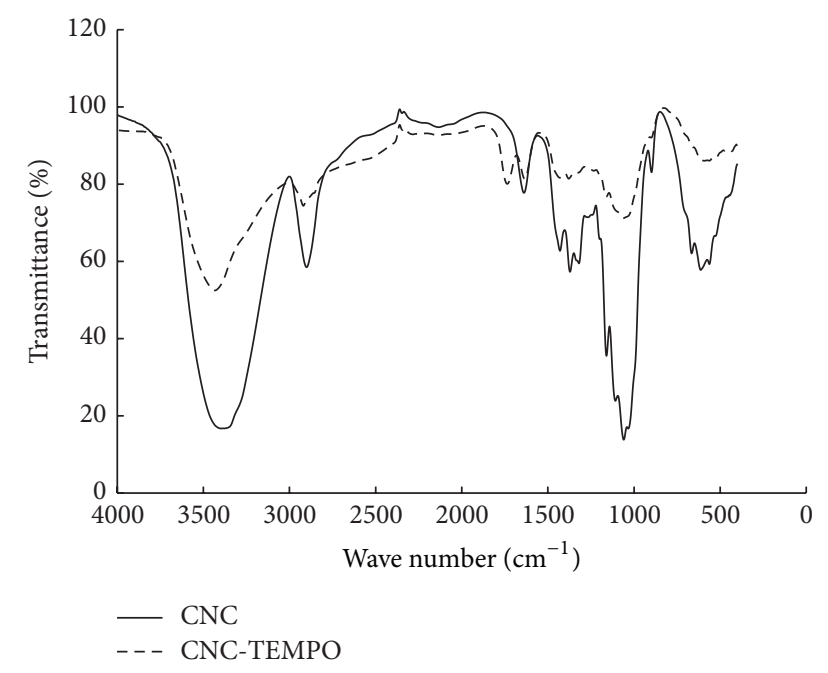

FIGURE 2: FTIR spectra of olive stones CNC and CNC-TEMPO.

at $1735 \mathrm{~cm}^{-1}$ due to the carbonyl group of the carboxylic groups. In addition, a shift of the $\mathrm{O}-\mathrm{H}$ stretching vibration to $3430 \mathrm{~cm}^{-1}$ occurred due to the introduced carboxylic acid hydroxyl groups.

3.1. Properties of Chitosan Nanocomposites Films. The isolated olive stones CNC and CNC/TEMPO were used with chitosan polymer to prepare nanocomposites films by casting/evaporation method. The prepared chitosan/cellulose nanocrystals films containing $2.5-10 \%$ of cellulose nanocrystals had good transparency due to the nanosize of cellulose nanocrystals. The high transparency of nanocomposites containing cellulose nanocrystals was reported before $[9,11,12]$. However, SEM images in Figure 3 showed aggregates of CNC and CNC-TEMPO in the chitosan films containing high contents of the nanocrystals. These aggregates were in the range from about 100 to $200 \mathrm{~nm}$ in width; no noticeable difference in diameter of these aggregates in case of using $\mathrm{CNC}$ or CNCTEMPO was noticed. This aggregation phenomenon can be attributed to strong hydrogen bonding and van der Waals forces between the nanocrystals [11].

The prepared nanocomposites films were characterized regarding their crystallinity and tensile strength properties. Figure 4 shows X-ray diffraction patterns of neat chitosan and the prepared chitosan/cellulose nanocrystals nanocomposites. The as-casted chitosan showed diffraction pattern of broad peak centered at about $2 \theta$ angle of 22 and another broad peak of lower intensity at about $2-\theta=12$. The peak at $2-\theta$ $=12$ indicated a hydrated crystalline structure, whereas the broad halo peak at $2-\theta=22$ indicated an amorphous structure of chitosan [31]. The broadening of the peaks indicates high amorphous nature of neat chitosan film.

Addition of nanocrystals to chitosan matrix resulted in diffraction patterns with two peaks at $2-\theta$ angles of 20 and 22 , which belong to both of cellulose nanocrystals and chitosan. In addition, peaks with higher intensity appeared at $2 \theta=8$ and 12 , which belong to chitosan were appeared. The intensity of the peaks at $2-\theta$ of 8 and 12 increased with increasing the ratio of cellulose nanocrystals in chitosan films. The appearance of these peaks indicates that presence of the nanocrystals increases the ordering of chitosan chains upon drying. This is in accordance with previous findings, which concluded that trans-crystallization of chitosan took place in the presence of cellulose nanocrystals [31]. Trans-crystallization occurred as a result of orientation of a semicrystalline polymer matrix perpendicularly to the cellulose nanocrystals [31].

Comparing XRD pattern of chitosan nanocomposite containing $\mathrm{CNC}$ to that containing CNC-TEMPO shows that the intensity of the peaks at $2-\theta$ of 8 and 12 were higher in case of nanocomposites containing CNC. This indicates higher crystallinity for nanocomposites containing $\mathrm{CNC}$ than those containing CNC-TEMPO.

Tensile strength properties of nanocomposites films were tested and the results are shown in Figure 5. As the figure shows, addition of CNC or CNC-TEMPO to chitosan resulted in remarkable increase of its tensile strength up to nanocrystals loading of $5 \%$, above which a decrease in tensile strength took place. In case of $\mathrm{CNC}$, the increase in tensile strength ranged from $33 \%$ to $40 \%$ on using 2.5 and $5 \%$ of CNC, respectively, while the increase in tensile strength ranged from $36 \%$ to $59 \%$ on using 2.5 and $5 \%$ of CNC-TEMPO. The higher tensile strength properties of nanocomposites containing CNC-TEMPO than those containing $\mathrm{CNC}$ could be attributed to the stronger ionic interaction between the negatively charged CNC-TEMPO and the positively charged chitosan chains. The remarkable effect of CNC and CNC-TEMPO on tensile strength at the low ratios of cellulose nanocrystals is attributed to their high aspect ratio and their very high surface area in addition to their homogeneous distribution in chitosan films. The high reinforcing effect of cellulose nanocrystals could be assigned also as already reported to a mechanical percolation phenomenon of cellulose nanocrystals which form a stiff continuous network of cellulosic nanoparticles linked through hydrogen bonding. The formation of this continuous network is supposed to form above the percolation threshold of the rod-like nanocrystals. The decrease in tensile strength above 5\% CNC could be due to the potential aggregation of cellulose nanocrystals, as seen in SEM images (Figure 3). It was noticed that the decrease in tensile strength due to addition of the nanocrystals at loading above $5 \%$ was higher in case of CNC-TEMPO than in case of CNC. This could be due to stronger aggregation of CNC-TEMPO and stronger hydrogen bonding than in case of CNC, that is, higher extent of aggregation in case of CNC-TEMPO. Similarly, Young's modulus increased with increasing the nanocrystals ratios up to $5 \%$ and then decreased. The increase in tensile modulus was 11 and $34 \%$ on adding 2.5 and 5\% of CNC-TEMPO while the increase was 17 and $35 \%$ in case of using CNC. The decrease of tensile modulus and tensile strength above $5 \%$ CNC-TEMPO loading could be due to aggregation of cellulose nanocrystals at high ratios as mentioned above. Addition of cellulose nanocrystals to chitosan film resulted in decreasing its strain at maximum load. This could be attributed to the higher stiffness of cellulose nanocrystals than chitosan matrix. The decrease in strain at break ranged 


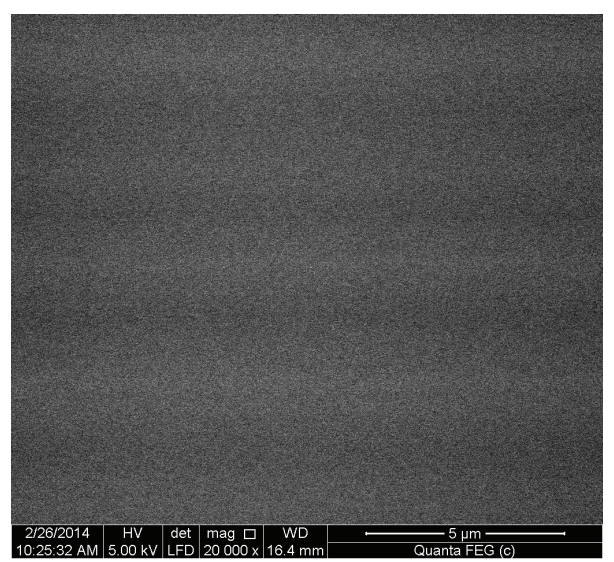

(a)

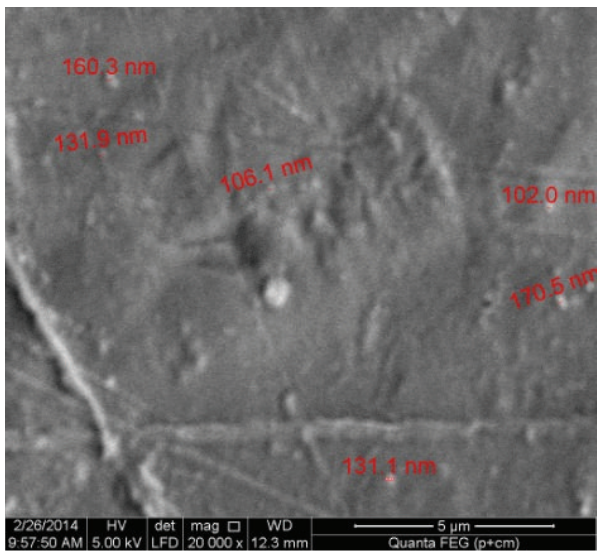

(b)

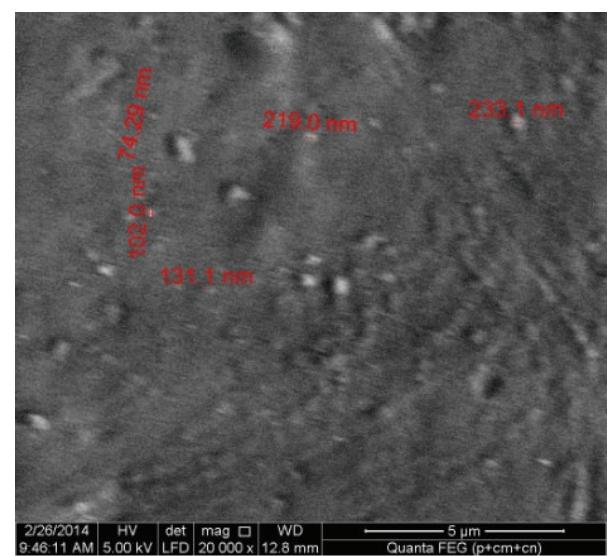

(c)

FIGURE 3: SEM of chitosan (a), chitosan containing 10\% CNC (b), and chitosan containing 10\% CNC-TEMPO (c).

from $56 \%$ to $82 \%$ upon addition $2.5 \%$ to $10 \%$ of CNC-TEMPO while the decrease was $66 \%$ to $75 \%$ upon addition $2.5 \%$ to $10 \%$ of CNC.

3.2. In Vitro Bioactivity Tests in SBF. Bioactivity of the prepared chitosan nanocomposites was investigated using soaking in simulated body fluid (SBF) test. The test can determine weight loss of biomaterials in SBF as well as formation of new hydroxyapatite at the surface of biomaterial under test. The rate of dissolution/degradation of biomaterials in SBF is an important factor for materials used in tissue engineering. For successful application of biomaterials in tissue engineering, the rate of degradation should be comparable to the rate of formation of new tissue in the body. The rate of formation and amount of the newly formed hydroxyapatite is as important as the rate of degradation of biomaterials in SBF.

Use of chitosan as a biomaterial in tissue engineering has been widely investigated. Various treatments including glutaraldehyde cross-linking, phosphorylation, calcium hydroxide, and calcium chloride treatment have been promoted to enhance the in vitro biomineralization of chitosan [3235]. Chitosan could be also mixed with previously prepared hydroxyapatite to nucleate and induce formation of new hydroxyapatite [36]. The use of cellulosic nanomaterials in tissue engineering is a fast-growing trend due to the inherent properties of cellulose as a biodegradable and biocompatible material and the nanosize advantages such as high surface area and porosity.

In the current work, bioactivity and dissolution of chitosan/cellulose nanocrystals nanocomposites were investigated. Figure 6 shows dissolution of chitosan and chitosan nanocomposites in SBF. As shown in the figure, chitosan is characterized by fast dissolution in SBF; almost complete dissolution of chitosan in SBF took place after two weeks of immersion in SBF. Presence of cellulose nanocrystals with chitosan, even at the lowest ratio, resulted in significant decrease in rate of dissolution of chitosan nanocomposites. The higher the ratio of cellulose nanocrystals the lower the rate of degradation of chitosan nanocomposites. At low cellulose nanocrystals loading (2.5\%), the dissolution of chitosan containing CNC-TEMPO in SBF was higher than that containing $\mathrm{CNC}$ while at higher ratios of cellulose nanocrystals no significant difference was found in amount of dissolution. After four weeks of immersion in SBF, the percentage of degraded chitosan nanocomposites was $45 \%$ 

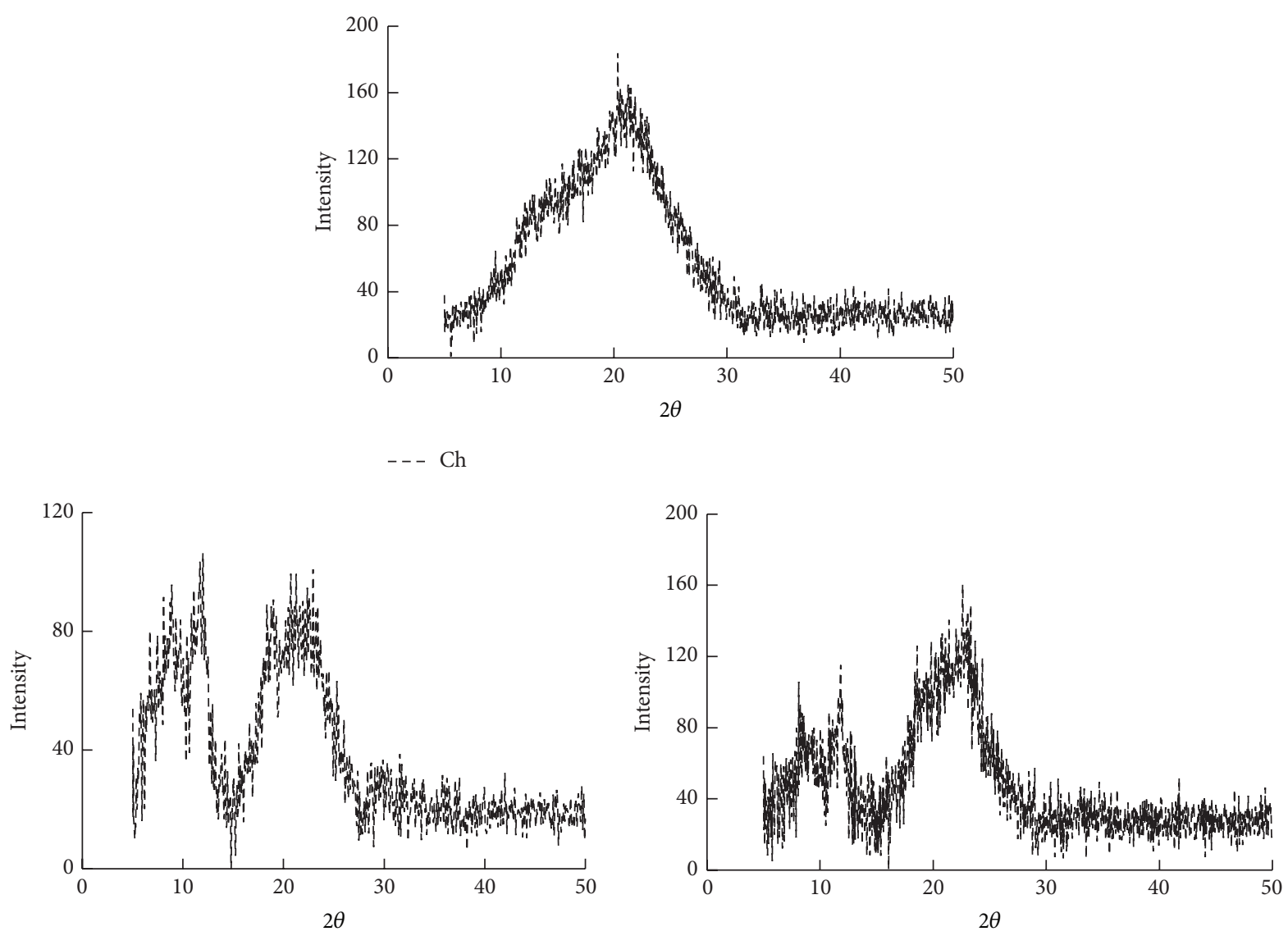

- - $\mathrm{Ch}+2.5 \mathrm{CNC}$
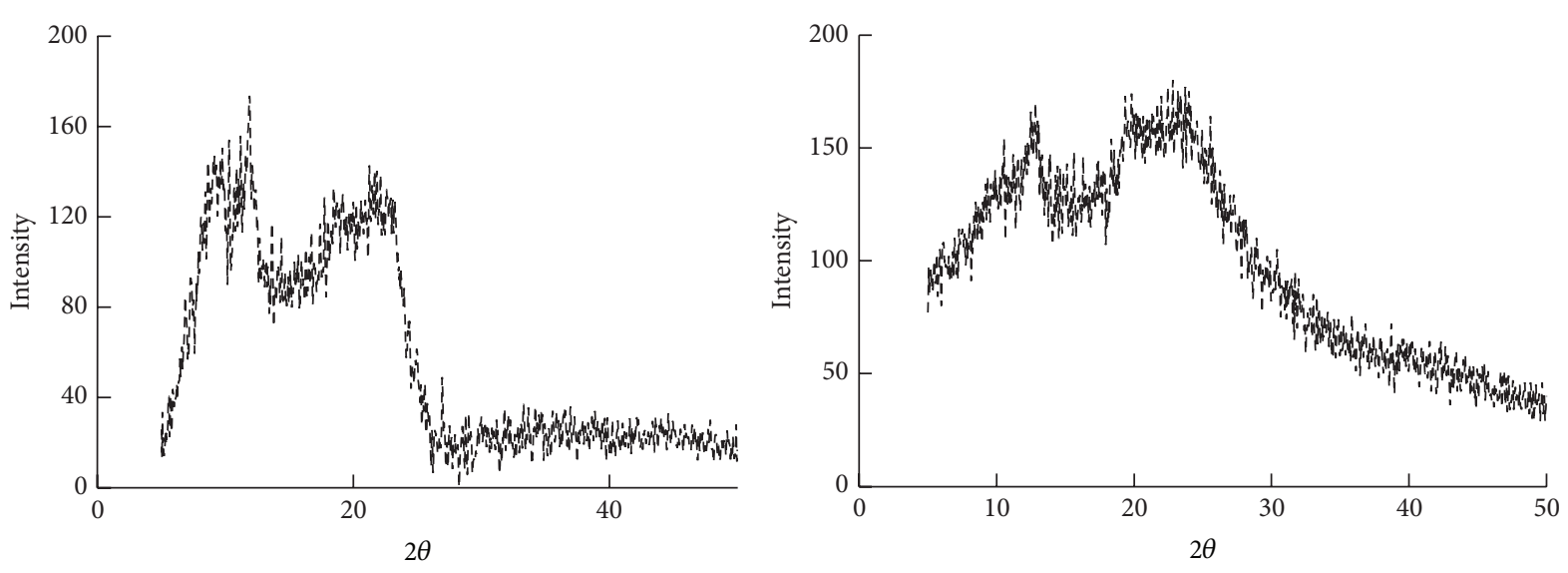

- - $\mathrm{Ch}+10 \mathrm{CNC}$

- - $\mathrm{Ch}+10 \mathrm{CNC}-\mathrm{TEMPO}$

FIGURE 4: XRD diffraction patterns of chitosan and chitosan nanocomposites containing 2.5 and $10 \%$ of CNC and CNC-TEMPO.

and $61 \%$ for nanocomposites containing $2.5 \%$ of $\mathrm{CNC}$ and CNC-TEMPO, respectively, while it was about $24 \%$ for nanocomposites containing $10 \%$ of CNC or CNC-TEMPO.

Regarding formation of hydroxyapatite, SEM images (Figure 7) showed that both of chitosan and chitosan/cellulose nanocrystals nanocomposites cannot induce noticeable formation of new hydroxyapatite at their surfaces. EDX analysis showed presence of very small amounts of
$\mathrm{Ca}$ and $\mathrm{P}$ at the surface of the different chitosan/cellulose nanocrystals nanocomposites as well as neat chitosan. The inability of carboxylate groups at the surface of the nanocrystals in case of using CNC-TEMPO to induce nucleation and formation of hydroxyapatite could be due the involvement these groups in strong ionic interaction with chitosan.

In other sets of experiments chitosan containing nanohydroxyapatite (HAp) at a fixed ratio of $2: 1$ of chitosan 

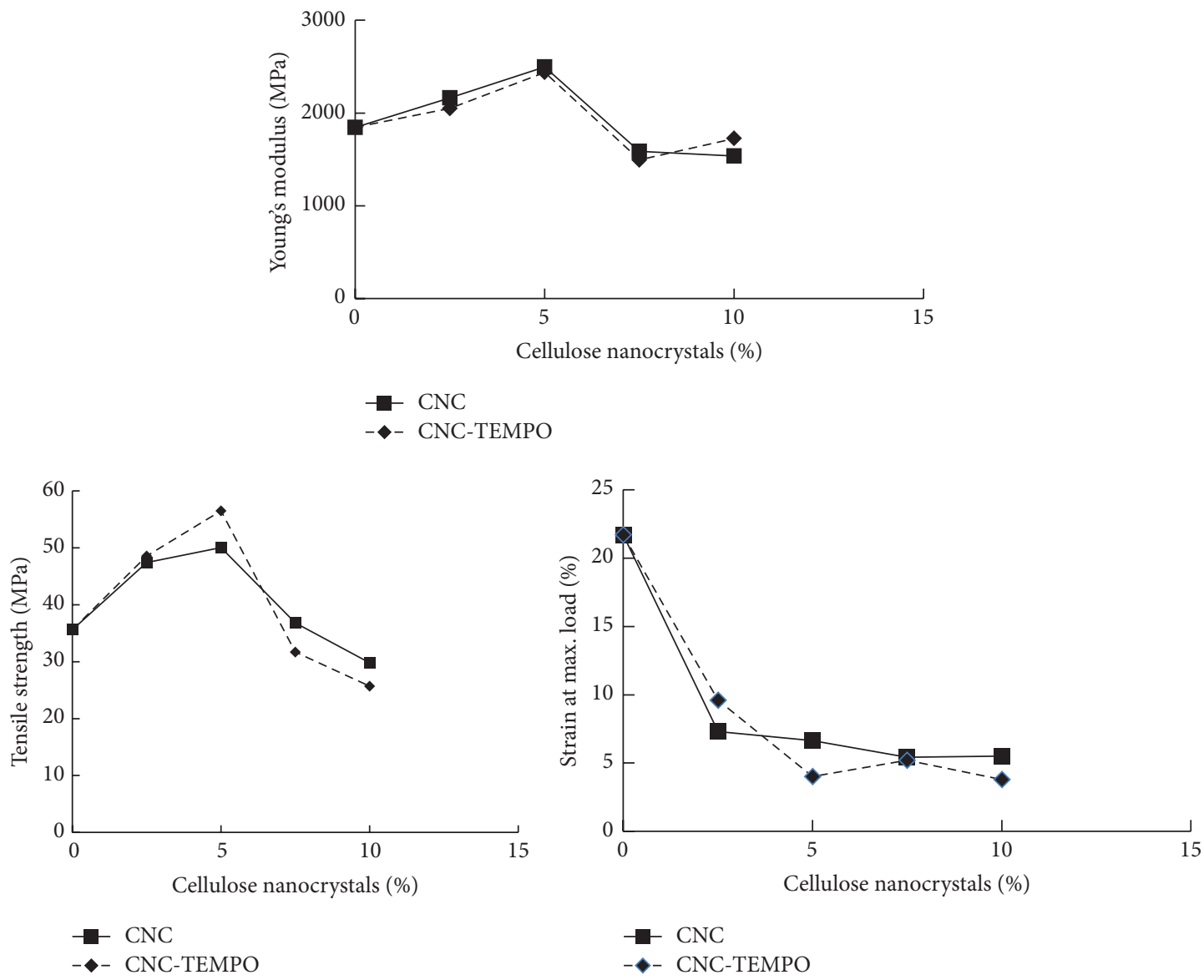

FIGURE 5: Tensile strength properties of chitosan and chitosan nanocomposites.
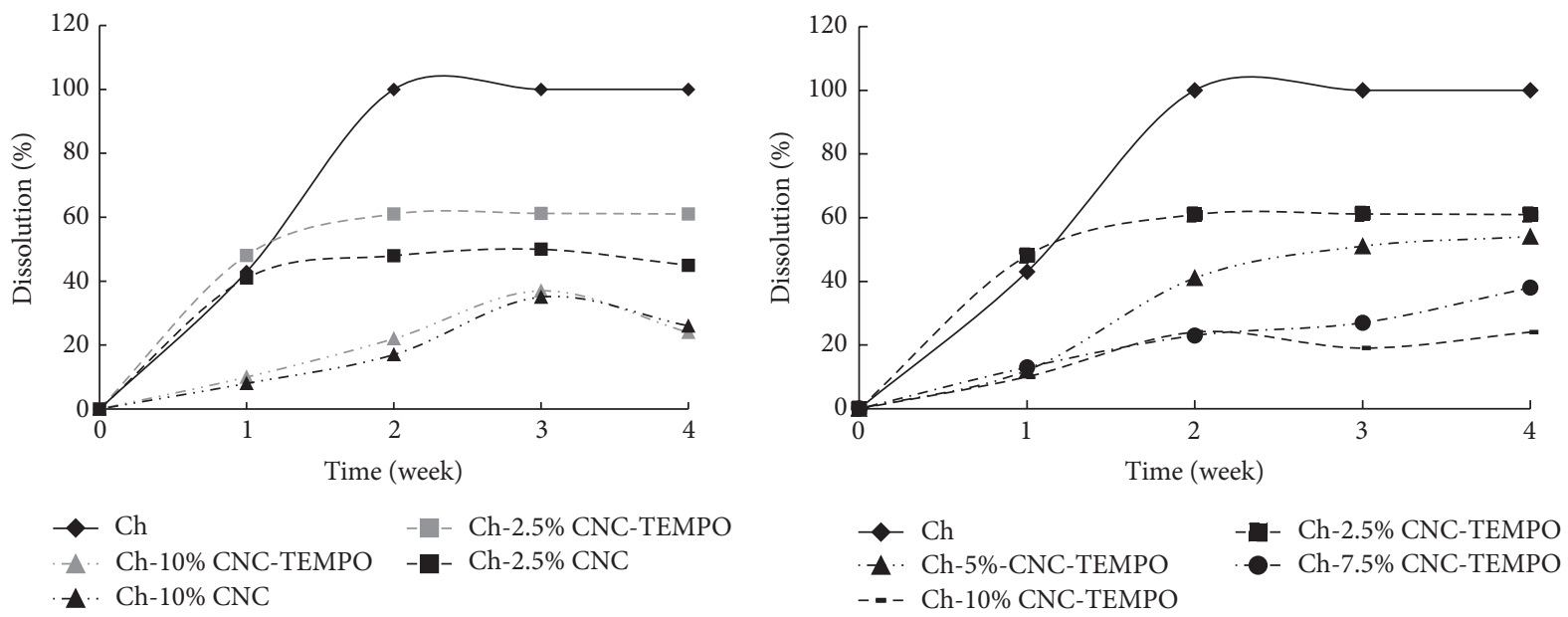

FIGURE 6: Dissolution of chitosan nanocomposites by $\mathrm{SBF}$ at $37^{\circ} \mathrm{C}$ at different intervals.

to hydroxyapatite was used with cellulose nanocrystals to prepare chitosan/hydroxyapatite/cellulose nanocrystals nanocomposites with different ratios of cellulose nanocrystals (CNC or CNC-TEMPO). Figure 8 shows TEM image of the nanohydroxyapatite used. The prepared nanocomposites were characterized regarding their dissolution in SBF and formation of hydroxyapatite. Figure 9 showed dissolution of these nanocomposites in SBF with time. As shown in the figure, nanocomposites containing chitosan and HAp had higher rate of dissolution in SBF than those containing chitosan, HAp, and cellulose nanocrystals. After two weeks of immersion in SBF, most of chitosan/HAp sample was 


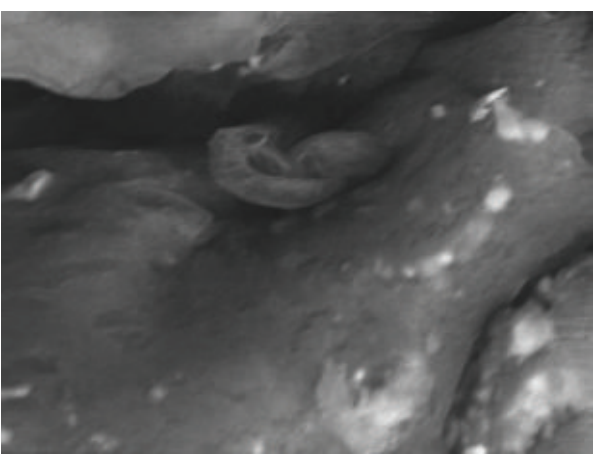

1000x

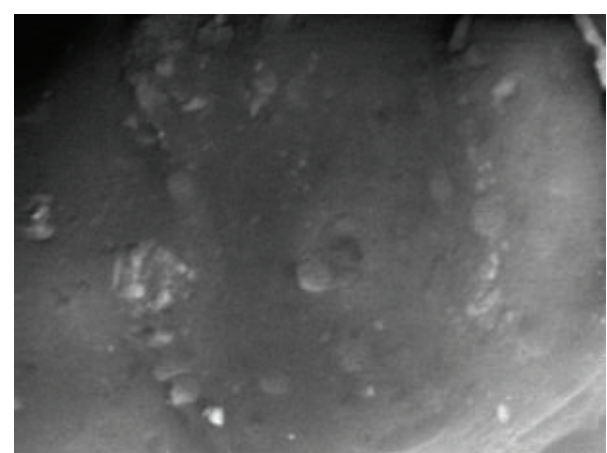

1000x

(a)

(b)

FIgURE 7: SEM images of chitosan (a) and chitosan/10\% CNC (b) after immersion in SBF for 4 weeks at $37^{\circ} \mathrm{C}$.

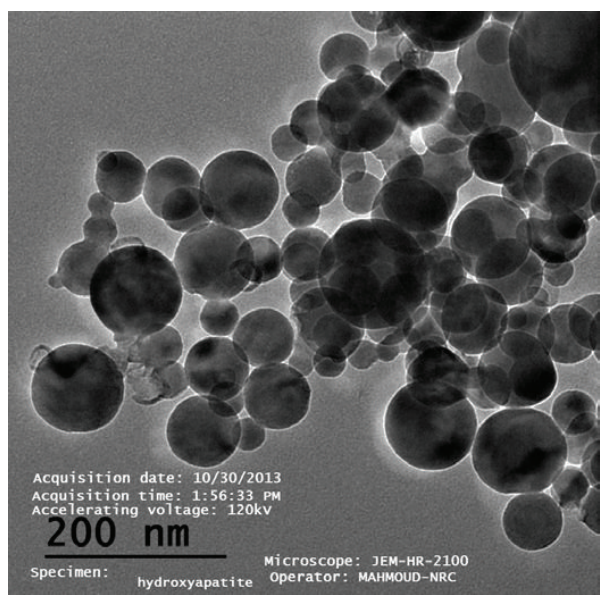

FIGURE 8: TEM of nanohydroxyapatite used in chitosan/CNC nanocomposites.
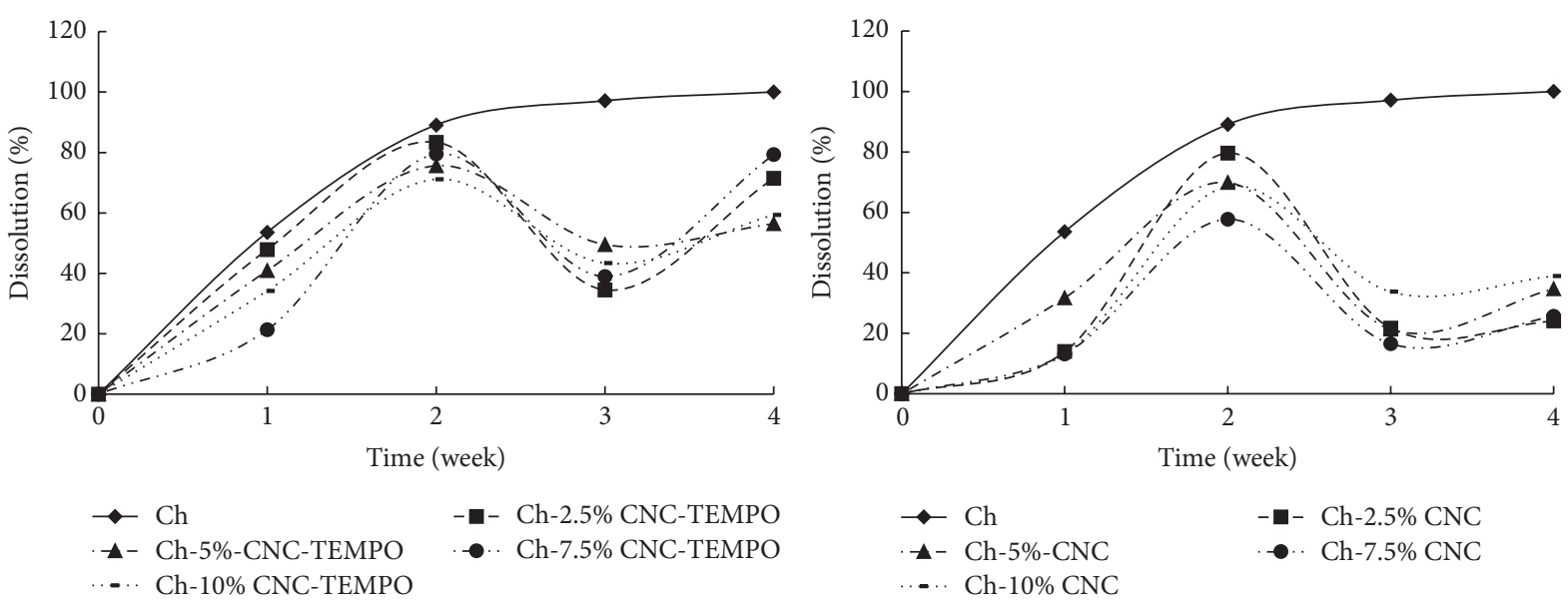

FIGURE 9: Dissolution of chitosan/cellulose nanocrystals nanocomposites containing nanohydroxyapatite by SBF at $37^{\circ} \mathrm{C}$ at different intervals.

dissolved. On the other hand, nanocomposites containing chitosan, HAp, and cellulose nanocrystals showed lower rate of dissolution as well as different profile of weight loss in SBF than chitosan. After two weeks, due to increasing amounts of newly formed HAp at chitosan surface of
chitosan/HAp/cellulose nanocrystals nanocomposites, there was weight gain and therefore the calculated dissolution in SBF decreased. But the decrease in weight loss, that is, more weight gain due to formation HAp, of chitosan/HAp/cellulose nanocrystals nanocomposites containing CNC-TEMPO in 


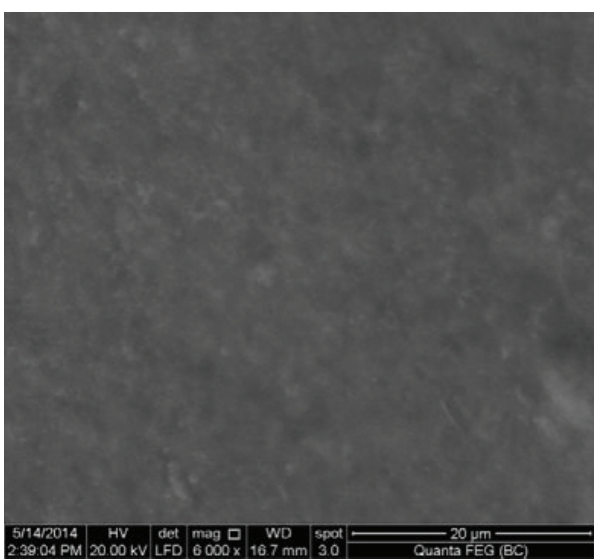

(a)

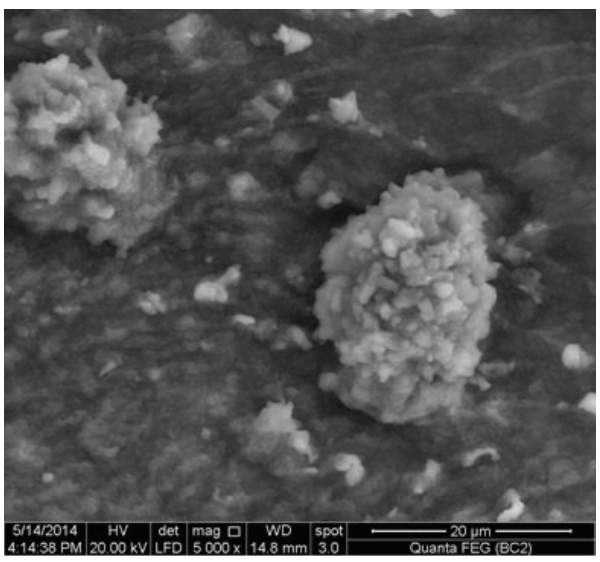

(c)

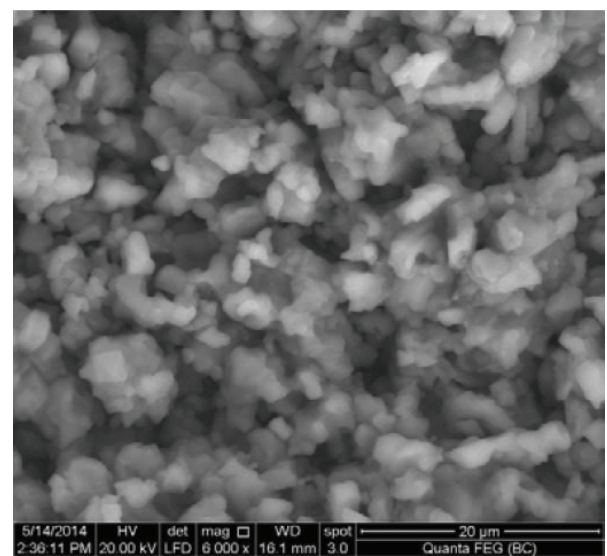

(b)

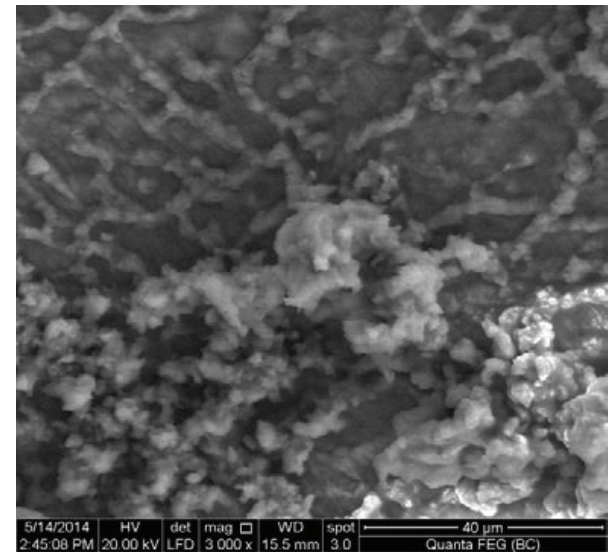

(d)

FIGURE 10: SEM of (a) chitosan/HAp nanocomposites before immersion in SBF, (b) chitosan/HAp nanocomposites after immersion in SBF for 2 weeks, (c) chitosan/HAp/10\% CNC after immersion in SBF for 2 weeks, and (d) chitosan/HAp/10\% CNC-TEMPO after immersion in $\mathrm{SBF}$ for 2 weeks at $37^{\circ} \mathrm{C}$.

SBF was higher than those containing CNC. This indicates higher amounts of HAp formation in case of using $\mathrm{CNC}$ than using CNC-TEMPO. This could be attributed to the higher rate of dissolution of the nanocomposites containing CNC-TEMPO than those containing CNC as discussed above. At longer time of immersion in SBF up to 4 weeks, the dissolution of chitosan/HAp/cellulose nanocrystals nanocomposites in the SBF tended to increase again. This could be due to increase in the rate of dissolution of chitosan more than rate of formation of new hydroxyapatite. SEM images in Figure 10 shows surfaces of the different chitosan nanocomposites after immersion in SBF for 2 weeks. The images showed presence of nucleated HAp at the surface of chitosan/HAp nanocomposites as well as presence of residual sodium chloride from SBF used. EDX analysis of depositions at the surface of chitosan nanocomposites showed formation of new HAp in addition to presence of sodium chloride, which is the major component of SBF used (Figure 11). Previous studies also showed the presence of $\mathrm{Ca}$ and $\mathrm{P}$ along with other elements such as $\mathrm{Na}, \mathrm{K}, \mathrm{Mg}, \mathrm{C}, \mathrm{O}$, and $\mathrm{Cl}$ when observed by EDX after the immersion in SBF [37].
The $\mathrm{Ca} / \mathrm{P}$ ratio of the newly formed HAp particles was $1.52,1.48$, and 1.55 for chitosan/HAp, chitosan/HAp/CNC, and chitosan/HAp/CNC-TEMPO nanocomposites, respectively. These values indicate formation of calcium-deficient hydroxyapatite since the theoretical value of $\mathrm{Ca} / \mathrm{P}$ of hydroxyapatite is 1.67 [32].

\section{Conclusions}

Cellulose nanocrystals and TEMPO-oxidized cellulose nanocrystals from olive stones can be used to increase tensile strength properties of chitosan. Due to the higher negative charge of TEMPO-oxidized cellulose nanocrystals, they resulted in higher tensile strength of chitosan at $2.5-5 \%$ loading. Chitosan/cellulose nanocrystals nanocomposites could not induce formation of noticeable amounts of hydroxyapatite upon soaking in simulated body fluid. However, cellulose nanocrystals (modified and unmodified) can be used to control and remarkably decrease the rate of dissolution of chitosan in simulated body fluid. Addition of nanohydroxyapatite to chitosan/cellulose nanocrystals 
kV: 20.0 Tilt: 0.0 Take-off: 42.1 Det typeSDD Apollo 40 Res.: 136 Amp. T: 12.8

FS: 483 Lsec: 23

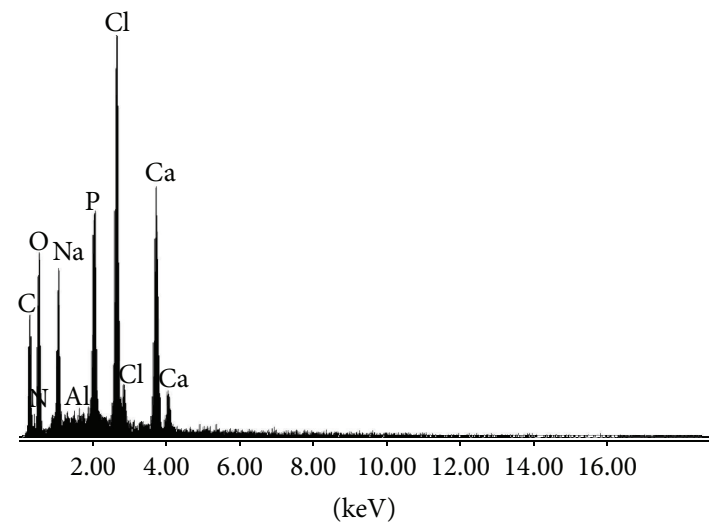

(a)

kV: 20.0 Tilt: 0.0 Take-off: 43.4 Det typeSDD Apollo 40 Res.: 136 Amp. T: 12.8 FS: 839 Lsec: 26

kV: 20.0 Tilt: 0.0 Take-off: 41.8 Det typeSDD Apollo 40 Res.: 136 Amp. T: 12.8 FS: 569 Lsec: 21

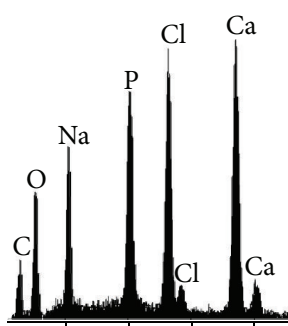

$\begin{array}{lllllllll}1.00 & 2.00 & 3.00 & 4.00 & 5.00 & 6.00 & 7.00 & 8.00 & 9.00\end{array}$

$(\mathrm{keV})$

(b)

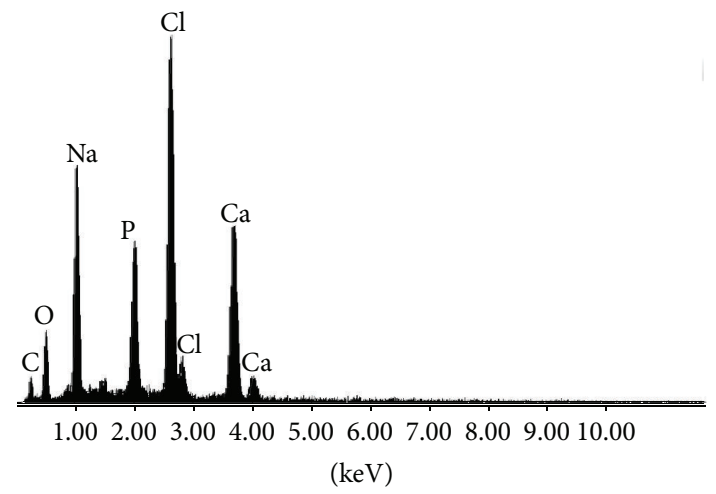

(c)

FIGURE 11: EDX spectra of (a) chitosan/HAp nanocomposites after immersion in SBF for 2 weeks, (b) chitosan/HAp/10\% CNC after immersion in SBF for 2 weeks, and (c) chitosan/HAp/10\% CNCTEMPO after immersion in SBF for 2 weeks at $37^{\circ} \mathrm{C}$.

composites could induce formation of hydroxyapatite upon soaking the nanocomposites in simulated body fluid. Due to higher rate of dissolution of chitosan/CNC-TEMPO in $\mathrm{SBF}$ than chitosan-CNC, the later showed higher increase in weight due to deposition of new hydroxyapatite.

\section{Conflict of Interests}

The authors declare that there is no conflict of interests regarding the publication of this paper.

\section{Acknowledgments}

The authors acknowledge the financial support of the current work by Egyptian Ministry of Higher Education and Scientific Research and Tunisian Ministry of Higher Education through the Egypt-Tunisia joint project entitled: Preparation and Characterization of Cellulosic Materials from Natural and Agricultural Wastes and Their Applications in Paper, Textiles, and Composites.

\section{References}

[1] D. Klemm, B. Heublein, H.-P. Fink, and A. Bohn, "Cellulose: fascinating biopolymer and sustainable raw material," Angewandte Chemie-International Edition, vol. 44, no. 22, pp. 33583393, 2005.

[2] C. K. S. Pillai, W. Paul, and C. P. Sharma, "Chitin and chitosan polymers: chemistry, solubility and fiber formation," Progress in Polymer Science, vol. 34, no. 7, pp. 641-678, 2009.

[3] E. I. Rabea, M. E.-T. Badawy, C. V. Stevens, G. Smagghe, and W. Steurbaut, "Chitosan as antimicrobial agent: applications and mode of action," Biomacromolecules, vol. 4, no. 6, pp. 1457-1465, 2003.

[4] A. Anitha, S. Sowmya, P. T. S. Kumar et al., "Chitin and chitosan in selected biomedical applications," Progress in Polymer Science, vol. 39, no. 9, pp. 1644-1667, 2014.

[5] F. Sun, K. Koh, S.-C. Ryu, D.-W. Han, and J. Lee, "Biocompatibility of nanoscale hydroxyapatite-embedded chitosan films," Bulletin of the Korean Chemical Society, vol. 33, no. 12, pp. 39503956, 2012. 
[6] D. Klemm, F. Kramer, S. Moritz et al., "Nanocelluloses: a new family of nature-based materials," Angewandte ChemieInternational Edition, vol. 50, no. 24, pp. 5438-5466, 2011.

[7] S. Beck-Candanedo, M. Roman, and D. G. Gray, "Effect of reaction conditions on the properties and behavior of wood cellulose nanocrystal suspensions," Biomacromolecules, vol. 6, no. 2, pp. 1048-1054, 2005.

[8] J. Araki, M. Wada, and S. Kuga, "Steric stabilization of a cellulose microcrystal suspension by poly(ethylene glycol) grafting," Langmuir, vol. 17, no. 1, pp. 21-27, 2001.

[9] M. Mariano, N. El Kissi, and A. Dufresne, "Cellulose nanocrystals and related nanocomposites: review of some properties and challenges," Journal of Polymer Science, Part B: Polymer Physics, vol. 52, no. 12, pp. 791-806, 2014.

[10] M. L. Hassan, J. Bras, E. A. Hassan, S. M. Fadel, and A. Dufresne, "Polycaprolactone/modified bagasse whisker nanocomposites with improved moisture-barrier and biodegradability properties," Journal of Applied Polymer Science. Special Issue: Biopolymersand Renewably Sourced Polymers, vol. 125, no. S2, pp. E10E19, 2012.

[11] Y. Habibi, L. A. Lucia, and O. J. Rojas, "Cellulose nanocrystals: chemistry, self-assembly, and applications," Chemical Reviews, vol. 110, no. 6, pp. 3479-3500, 2010.

[12] X. Cao, Y. Habibi, W. L. E. Magalhães, O. J. Rojas, and L. A. Lucia, "Cellulose nanocrystals-based nanocomposites: fruits of a novel biomass research and teaching platform," Current Science, vol. 100, no. 8, pp. 1172-1176, 2011.

[13] S. Kalia, A. Dufresne, B. M. Cherian et al., "Cellulose-based bioand nanocomposites: a review," International Journal of Polymer Science, vol. 2011, Article ID 837875, 35 pages, 2011.

[14] R. M. Domingues, M. E. Gomes, and R. L. Reis, "The potential of cellulose nanocrystals in tissue engineering strategies," Biomacromolecules, vol. 15, no. 7, pp. 2327-2346, 2014.

[15] R. Ghanbari, F. Anwar, K. M. Alkharfy, A.-H. Gilani, and N. Saari, "Valuable nutrients and functional bioactives in different parts of olive (Olea europaea L.) - a review," International Journal of Molecular Sciences, vol. 13, no. 3, pp. 3291-3340, 2012.

[16] G. Rodríguez, A. Lama, R. Rodríguez, A. Jiménez, R. Guillén, and J. Fernández-Bolaños, "Olive stone an attractive source of bioactive and valuable compounds," Bioresource Technology, vol. 99, no. 13, pp. 5261-5269, 2008.

[17] M. L. Hassan, R. E. Abou-Zeid, R. Khiari, S. M. Fadel, and M. El-Sakhawy, "Cellulose nanocrystals and carboxymethyl cellulose from olive stones and their use to improve paper sheets properties," International Journal of Nanoparticles, vol. 7, no. 3$4,2014$.

[18] G. Siqueira, J. Bras, and A. Dufresne, "Cellulosic bionanocomposites: a review of preparation, properties and applications," Polymers, vol. 2, no. 4, pp. 728-765, 2010.

[19] M. Pereda, A. Dufresne, M. I. Aranguren, and N. E. Marcovich, "Polyelectrolyte films based on chitosan/olive oil and reinforced with cellulose nanocrystals," Carbohydrate Polymers, vol. 101, no. 1, pp. 1018-1026, 2014.

[20] A. F. Miler and A. M. Donald, "Imaging of anisotropic cellulose suspensions using environmental scanning electron microscopy," Biomacromolecules, vol. 4, no. 3, pp. 510-517, 2003.

[21] F. Li, P. Biagioni, M. Finazzi, S. Tavazzi, and L. Piergiovanni, "Tunable green oxygen barrier through layer-by-layer selfassembly of chitosan and cellulose nanocrystals," Carbohydrate Polymers, vol. 92, no. 2, pp. 2128-2134, 2013.
[22] L. Sui, L. Huang, P. Podsiadlo, N. A. Kotov, and J. Kieffer, "Brillouin light scattering investigation of the mechanical properties of layer-by-layer assembled cellulose nanocrystal films," Macromolecules, vol. 43, no. 22, pp. 9541-9548, 2010.

[23] Q. Li, J. Zhou, and L. Zhang, "Structure and properties of the nanocomposite films of chitosan reinforced with cellulose whiskers," Journal of Polymer Science, Part B: Polymer Physics, vol. 47, no. 11, pp. 1069-1077, 2009.

[24] J. P. de Mesquita, C. L. Donnici, I. F. Teixeira, and F. V. Pereira, "Bio-based nanocomposites obtained through covalent linkage between chitosan and cellulose nanocrystals," Carbohydrate Polymers, vol. 90, no. 1, pp. 210-217, 2012.

[25] H. Wang and M. Roman, "Formation and properties of chitosan/cellulose nanocrystal polyelectrolyte macroion complexes for drug delivery applications," Biomacromolecules, vol. 12, no. 5, pp. 1585-1593, 2011.

[26] L. E. Wise, M. Murphy, and A. A. D’Addieco, "Chlorite holocellulose, its fractionation and bearing on summative wood analysis and on studies on hemicelluloses," Paper Trade Journal, vol. 122, no. 2, pp. 35-43, 1946.

[27] B. L. Browning, Methods of Wood Chemistry, Volume II, Interscience Publisher, New York, NY, USA, 1967.

[28] Y. Habibi, H. Chanzy, and M. R. Vignon, "TEMPO-mediated surface oxidation of cellulose whiskers," Cellulose, vol. 13, no. 6, pp. 679-687, 2006.

[29] I. Filpponen and D. S. Argyropoulos, "Regular linking of cellulose nanocrystals via click chemistry: synthesis and formation of cellulose nano-platelet gels," Biomacromolecules, vol. 11, no. 4, pp. 1060-1066, 2010.

[30] N. V. Ivanova, E. A. Korolenko, E. V. Korolik, and R. G. Zhbankov, "IR spectrum of cellulose," Journal of Applied Spectroscopy, vol. 51, no. 2, pp. 847-851, 1989.

[31] A. Khan, R. A. Khan, S. Salmieri et al., "Mechanical and barrier properties of nanocrystalline cellulose reinforced chitosan based nanocomposite films," Carbohydrate Polymers, vol. 90, no. 4, pp. 1601-1608, 2012.

[32] C. G. Aimoli and M. M. Beppu, "Precipitation of calcium phosphate and calcium carbonate induced over chitosan membranes: a quick method to evaluate the influence of polymeric matrices in heterogeneous calcification," Colloids and Surfaces B: Biointerfaces, vol. 53, no. 1, pp. 15-22, 2006.

[33] F. Fang, L. Yu, Z. Binyuan, and J. Ke'aoh, "The fabrication of biomimetic chitosan scaffolds by using SBF treatment with different crosslinking agents," Journal of Wuhan University of Technology-Materials Science Edition, vol. 20, pp. 20-24, 2005.

[34] Y. Yokogawa, K. Nishizawa, F. Nagata, and T. Kameyama, "Bioactive properties of chitin/chitosan-calcium phosphate composite materials," Journal of Sol-Gel Science and Technology, vol. 21, no. 1-2, pp. 105-113, 2001.

[35] H. K. Varma, Y. Yokogawa, F. F. Espinosa et al., "Porous calcium phosphate coating over phosphorylated chitosan film by a biomimetic method," Biomaterials, vol. 20, no. 9, pp. 879-884, 1999.

[36] S.-H. Lee, B.-J. Kim, S.-H. Shin et al., "Guided bone regeneration effect by chitosan/hydroxyapatite membrane on repair of rat calvarial defect," Tissue Engineering and Regenerative Medicine, vol. 6, no. 4-11, pp. 916-923, 2009.

[37] D. Baskar, R. Balu, and T. S. Kumar, "Mineralization of pristine chitosan film through biomimetic process," International Journal of Biological Macromolecules, vol. 49, no. 3, pp. 385-389, 2011. 

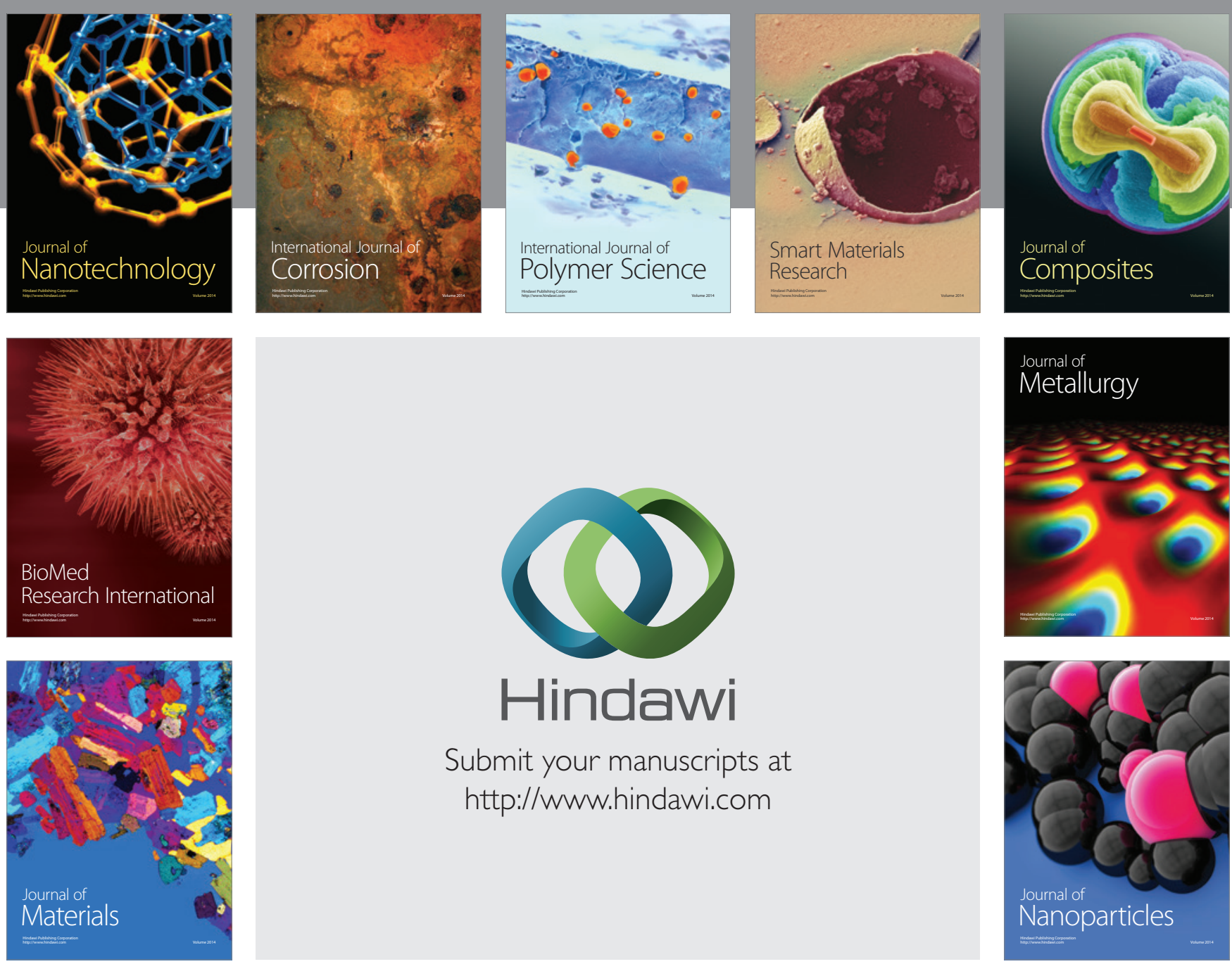

Submit your manuscripts at http://www.hindawi.com
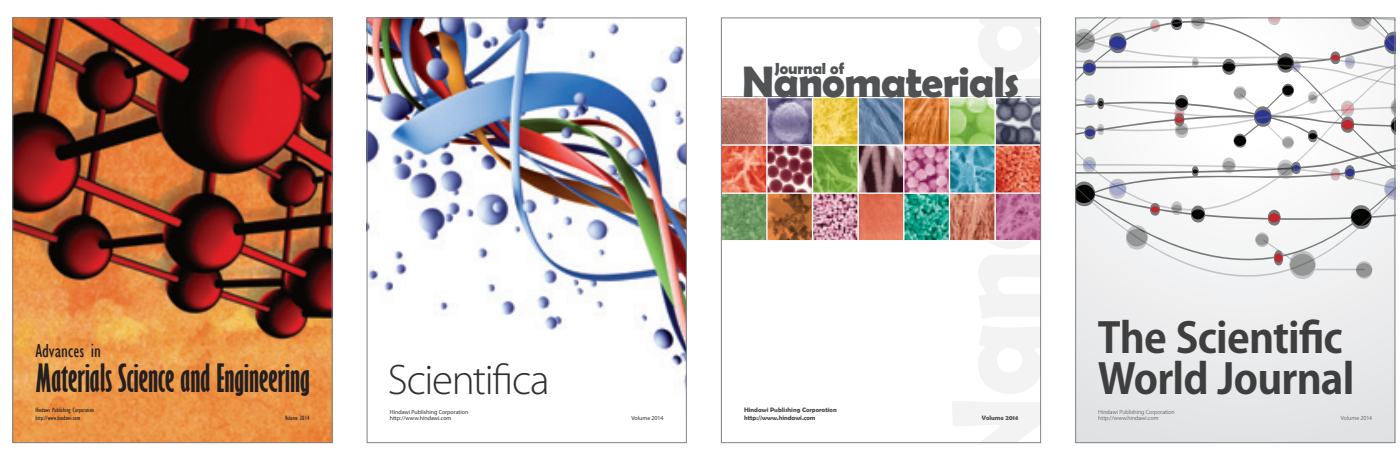

\section{The Scientific World Journal}
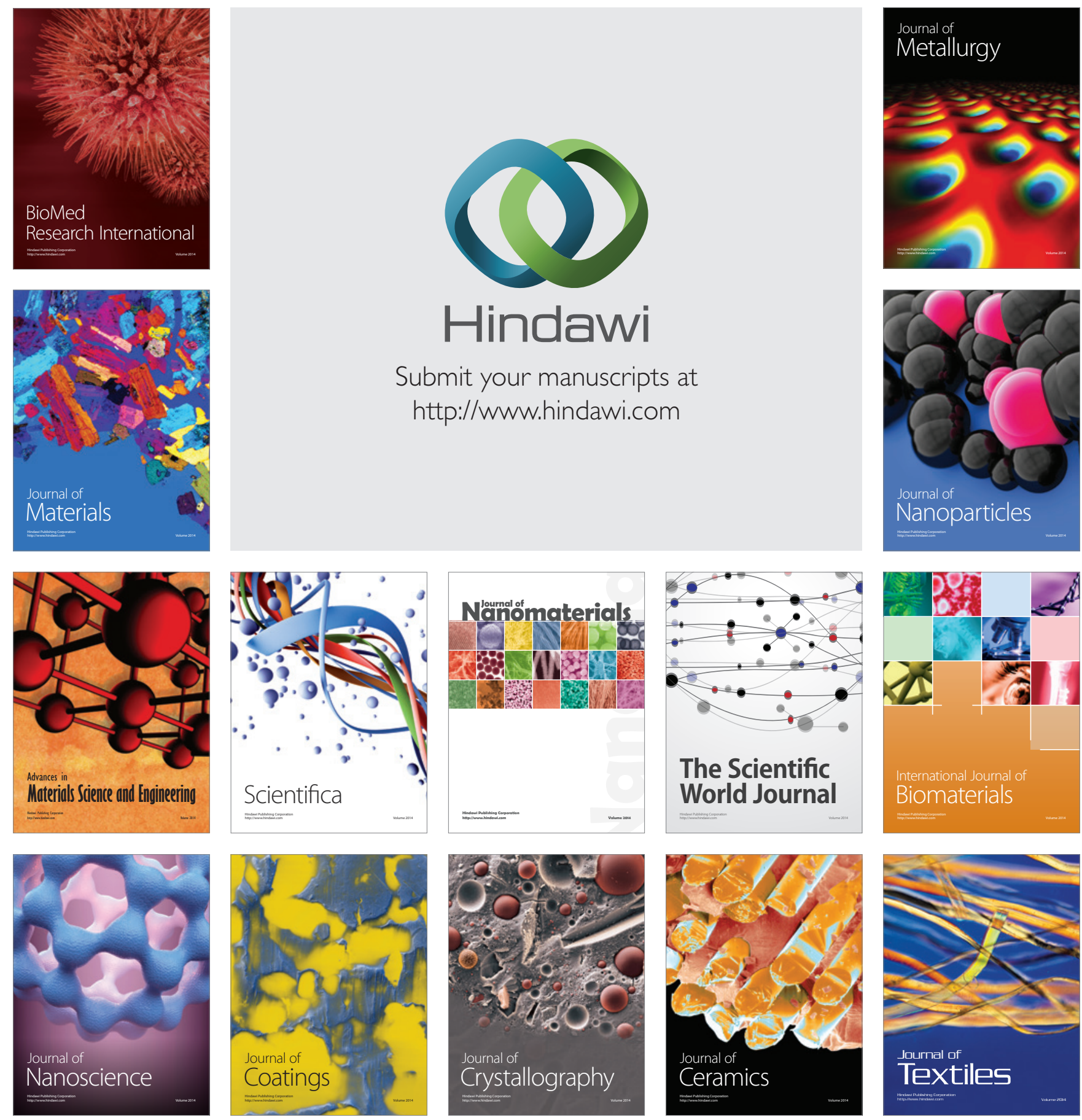